Research Article

\title{
Interactions between the Aryldiazonium Cations and Graphene Oxide: A DFT Study
}

\author{
Avni Berisha iD \\ Department of Chemistry, FNMS, University of Pristina "Hasan Prishtina", 10000 Pristina, Kosovo \\ Correspondence should be addressed to Avni Berisha; avni.berisha@uni-pr.edu
}

Received 10 December 2018; Accepted 6 February 2019; Published 26 February 2019

Academic Editor: Zhongfang Chen

Copyright ( 92019 Avni Berisha. This is an open access article distributed under the Creative Commons Attribution License, which permits unrestricted use, distribution, and reproduction in any medium, provided the original work is properly cited.

\begin{abstract}
Understanding the grafting behavior of the aryldiazonium cations is of fundamental and also of practical importance for the vast number of applications that involve the use of modified graphene oxide (from simple adsorption process to electronic and photovoltaic applications). In this work, the mechanism of the adsorption and grafting of diazonium cations on the graphene oxide surface was investigated by the use of density functional theory. Two types of aryldiazonium cations, one bearing only phenyl ring and the other nitrophenyl, were selected as adsorbates/grafted moiety. By evaluating the adsorption energies at 7 different positions onto the graphene oxide both in the gaseous and solvent phase (using COSMO approach), the most probable adsorption sites were found. Moreover, the most stable adsorption sites were used to calculate and plot NCI (noncovalent interactions). The obtained results are important as they not only give molecular insights regarding the nature of the interaction and its dependence on the adsorption site of the graphene oxide surface but also on the activation energy for such a grafting reaction to take place, providing a mechanistic aspect to understand these grafting reactions.
\end{abstract}

\section{Introduction}

Aryldiazonium cations have been widely applied in the surface modification reaction since the first pioneering work of Prof. Pinson in the 90s [1]. The use of aryldiazonium cations in contrast to other molecules used generally for modification reactions (thiols, silanes, phosphonic acids, etc.) [2] represents the most straight forward strategy to achieve surface modification of materials regardless of their chemical composition nor their conductivity, a feature that is lacking in the case of other molecules (i.e., although thiols offer an elegant way to achieve modification of noble metals, they are not applicable for surface modification of polymers (similar case stand for phosphonic or silanes which are applicable only in the case for surfaces that contain oxyhydroxy groups)) [3]. To date, the grafted layers derived through electrochemical [1, 3-6], sonochemical [7], or thermal dediazonation reactions have been characterized by a vast number of analytical methods (RBS, Tof-SIMS, XPS, IRRAS, AFM, TGA, etc.) [3]. The practical reasons why the modification of the graphene oxide surface through the use of aryldiazonium cations was performed were to give the material nanocarrier ability for the delivery of anticancer drugs [8], to improve its nonlinear optical performance [9], to influence the structure/property relationship in its nanocomposites with iron oxide nanoparticles [10], etc. In comparison with experimental methods, there is a lack of theoretical studies applied to understand the grafting/ adsorption of the aryldiazonium cations onto the graphene oxide. In the current study, we address the adsorption of the aryldiazonium cations, their binding energy, and the activation energy related with their grafting onto the graphene oxide by using DFT calculations.

\section{Computational Details}

The adsorption properties of aryldiazonium cations on graphene surfaces are investigated by the DFT method using the generalized gradient approximation (GGA) [11] or PBE [12-15]. The graphene oxide (GOx) model is approximated by using a $5 \times 5$ graphene model that contains epoxy, hydroxyl, and carboxy groups on its surface (Figure 1(a)).

While the model takes into account the influence of the different functional groups of the GOx surface onto the 


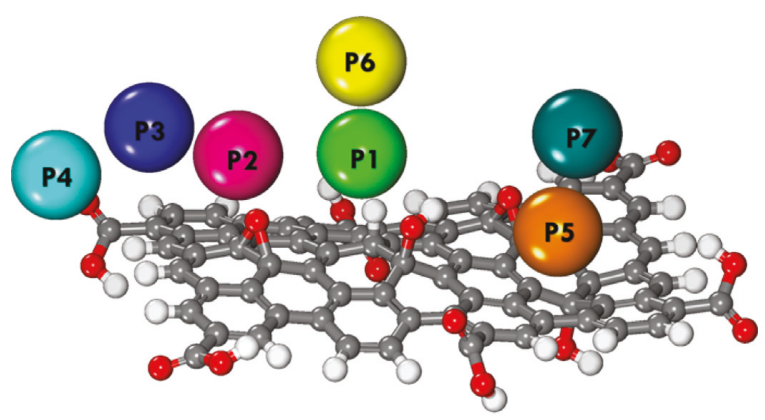

(a)

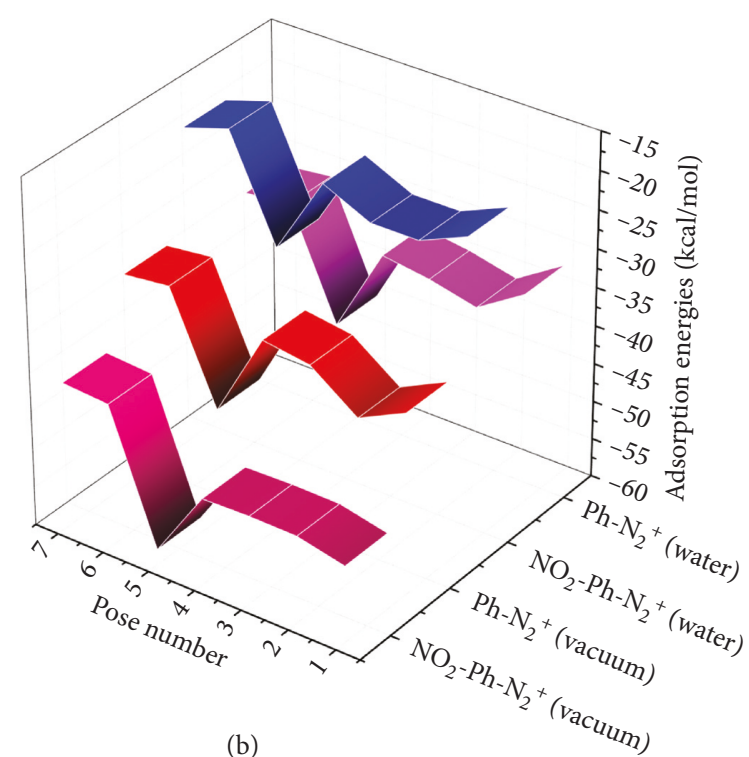

Figure 1: (a) Adsorption site positions for diazonium structures (P1-P5: flat lying onto the GOx surface; P6 and P7: perpendicular to the diazonium group oriented towards the GOx surface) and (b) the computed adsorption energies (in vacuum and water) of aryldiazonium cations onto the different GOx adsorption sites.

adsorption and the grafting of the aryldiazonium cations, the effect of the concentration of such surface groups is not considered in this work. This can also have an influence on the adsorption properties of the studied molecules $[16,17]$ but probably not an extensive impact during the grafting reaction of such moieties onto the GOx surface [3]. As already observed by the De Feyter group [18], the grafting of the aryl radical proceeds in mushroom-type (one root, many branches and leaves) of film formation, meaning that the whole surface is not completely covered with the aryl groups and that the radicals (responsible for the initial grafting) prefer to react with the first grafted group rather than with the surface; that is, the reaction is no more a surface reaction.

The calculations were based on the double-numeric quality with polarization functions (DNP) basis set $[19,20]$. The calculations in water were performed using COnductor-like Screening MOdel (COSMO) [21].

The adsorption energy, both in vacuum and water models, is evaluated as follows $[6,13,20]$ :

$$
E_{\text {interaction }}=E_{\mathrm{GOx} \text {-diazonium }}-\left(E_{\mathrm{GOx}}+E_{\text {diazonium }}\right) \text {, }
$$

where $E_{\mathrm{GOx} \text {-diazonium }}$ is the total energy of the adsorption system. $E_{\mathrm{GOx}}$ and $E_{\text {diazonium }}$ are the energies of the isolated graphene oxide and aryldiazonium cations, respectively. The transition state (in water) is computed using the combination of linear synchronous transit (LST) and quadratic synchronous transit (QST) [22].

\section{Results and Discussion}

Although the adsorption of the diazonium salts onto the metal surface is evidenced experimentally from corrosion measurements in the case of iron [3], the interaction energies, adsorption geometry, and the interaction type between the GOx surface and the aryldiazonium cations remain up to now unknown for the GOx surface. For the gold surface, the calculated bond dissociation energy (BDE) of the grafted aryl or alkyl moiety is $\approx 40 \mathrm{kcal} / \mathrm{mol}[6,12]$. The adsorption of the diazonium cation is the first step for the grafting reaction. In order to evaluate and understand the adsorption of the diazonium cations (and the substituent effect) onto the GOx surface, different adsorption sites were explored (Figure 1(a)). The calculated adsorption energies (Figure 1(b)) are in the range of -40 up to $-60 \mathrm{kcal} / \mathrm{mol}$ in the case of vacuum and -22 up to $-45 \mathrm{kcal} / \mathrm{mol}$ when the effect of the solvent is accounted. In all cases, the highest adsorption energies were obtained for the P5 adsorption position-when the aryldiazonium cations are adsorbed planary onto the phenyl rings of the GOx surface. The adsorption energy for the phenyldiazonium cation is $-45 \mathrm{kcal} / \mathrm{mol}$, a value that is slightly higher (nearly $-5 \mathrm{kcal} /$ $\mathrm{mol}$ ) than the adsorption energy of nitrophenyldiazonium cation. This suggests that the interaction mode is mainly a $\pi-\pi$ stacking one [23], so probably, the reason of the slightly lower adsorption energy for the nitrophenyl cation is the distortion of its planarity, decreasing its $\pi$ stacking ability with the GOx surface.

To asses correctly the interaction type [24], the NCI (noncovalent interaction) plot and the reduced density gradient (RDG) vs. $\operatorname{sign}(\lambda) \rho$ were computed [25] for the highest adsorption site. The visualization of the NCI surface (Figure $2(\mathrm{a})$ ) and the RDG vs. $\operatorname{sign}(\lambda) \rho$ supports that the adsorption interaction is a van der Waals one. The decreased adsorption energy for the nitrophenyl cation in comparison to the phenyl one is due to the repulsion interaction (this is evident in Figure 2, the plot part at the region of the 0.02 $\operatorname{sign}(\lambda) \rho$ value). 

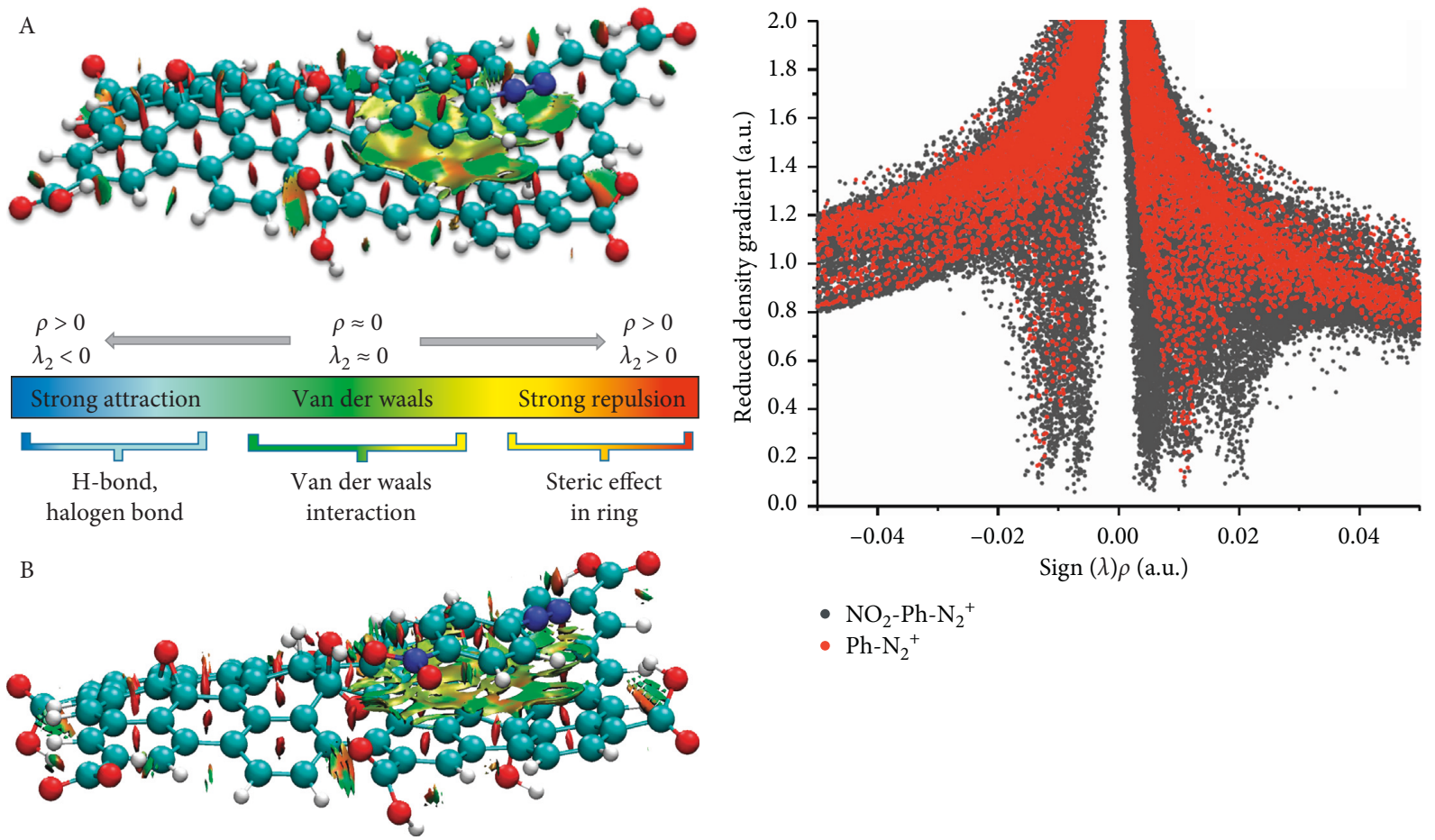

(a)

(b)

Figure 2: Noncovalent interaction surfaces (a) ((A) phenyldiazonium cation; (B) nitrophenyldiazonium cation) and (b) the plot of reduced density gradient (RDG) vs. $\operatorname{sign}(\lambda) \rho$ for the interaction of $\mathrm{GOx} / \mathrm{N}_{2}{ }^{+}-\mathrm{Ph}$ (red) and $\mathrm{GOx} / \mathrm{N}_{2}{ }^{+}-\mathrm{Ph}-\mathrm{NO}_{2}$ (black).

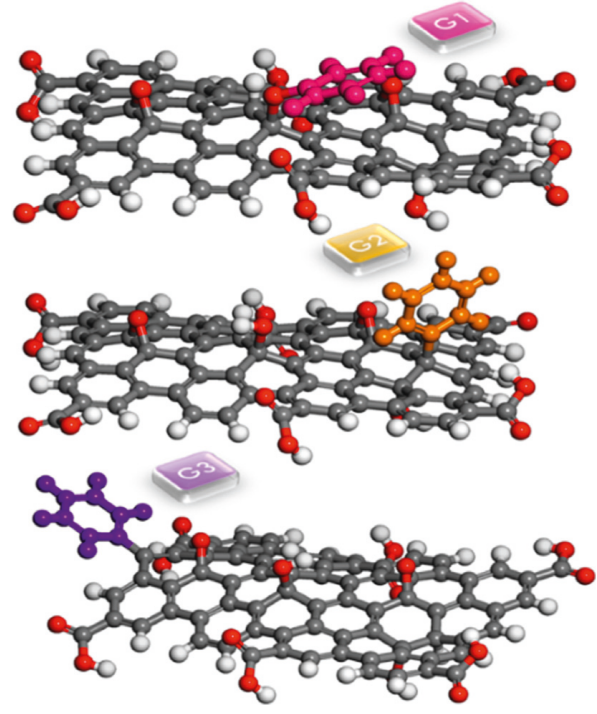

(a)

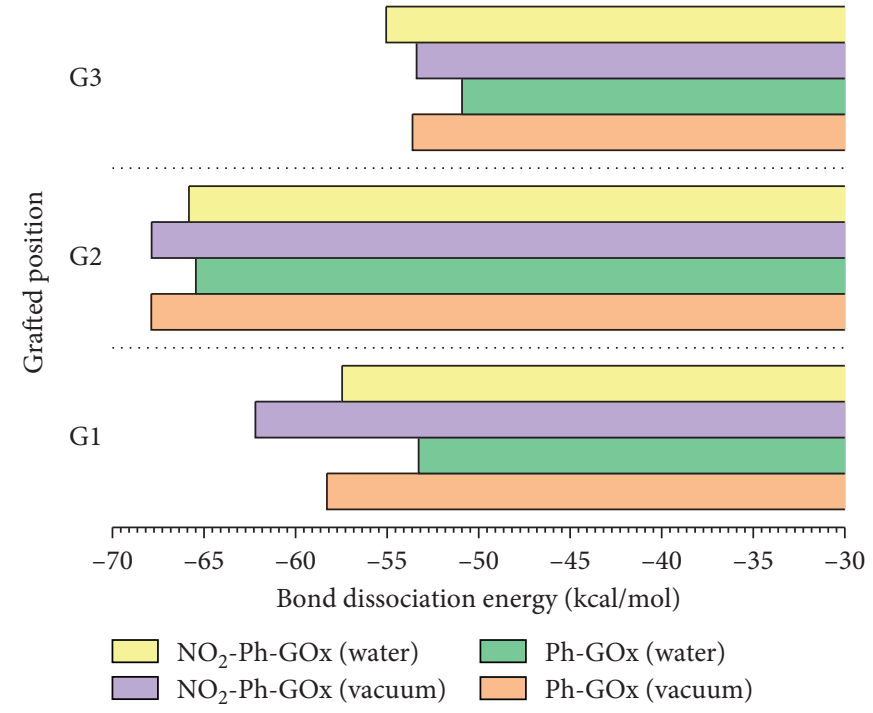

(b)

FIGURe 3: (a) Grafting positions (G1-G3) and (b) computed BDEs in vacuum and water (COSMO) for the bonding of phenyl radicals and nitrophenyl radicals at 3 distinctive grafting positions onto the GOx surface.

The dissociation energy for the grafted aryl groups is calculated for three different possible grafting positions (Figure 3, G1 to G3). The computed BDE values indicate that the most probable grafting position is at $\mathrm{G} 3$, which correlates well with the adsorption energy results as this is also the preferred adsorption site. The $\mathrm{BDE}$ in the case of solvent is $\approx 66 \mathrm{kcal} / \mathrm{mol}$ (Figure 3(b)).
The homolytic bond scission energy for the aryldiazonium cations (at $0 \mathrm{~K})\left(\mathrm{ArN}_{2}{ }^{+} \longrightarrow \mathrm{Ar}^{*}+\mathrm{N}_{2}\right)$ for the studied molecules, together with their corresponding transition states in the grafting reactions on the graphene oxide surface, is presented in Figure 4. The BDE for the phenyldiazonium cation is $32.4 \mathrm{kcal} / \mathrm{mol}$ and for the nitrophenyldiazonium cation is $36.1 \mathrm{kcal} / \mathrm{mol}$. Spontaneous grafting of the 

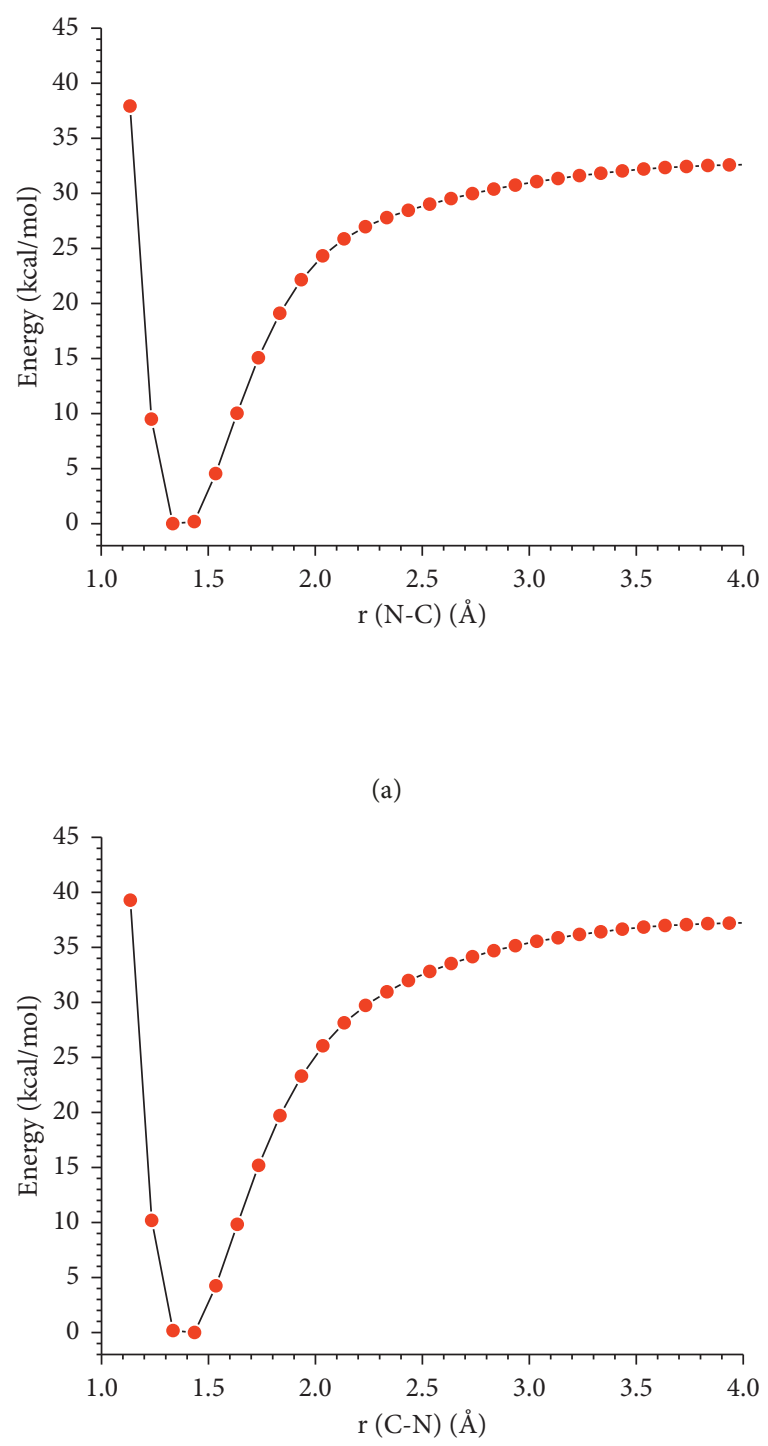

(c)

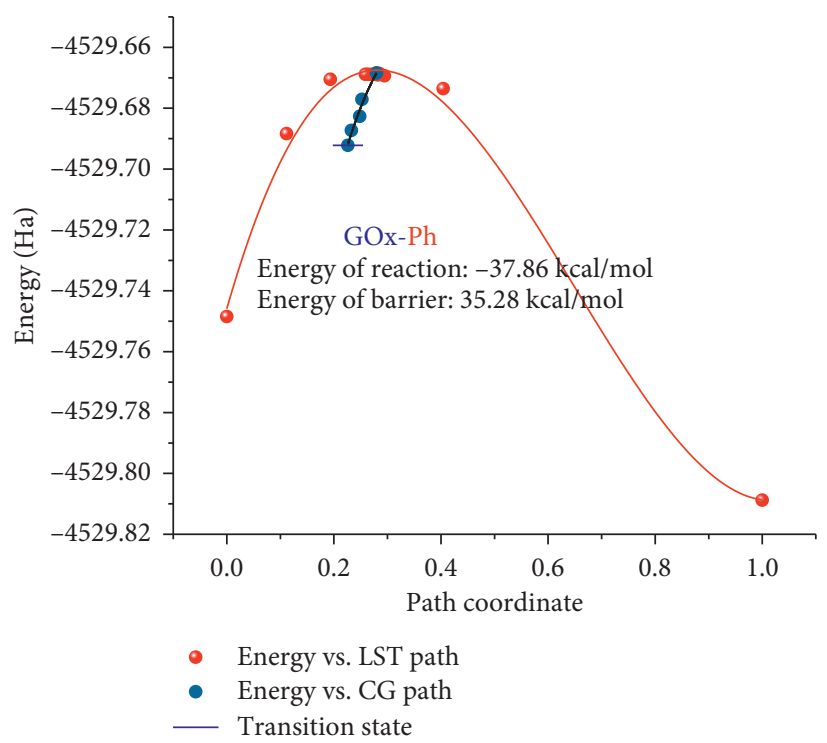

(b)

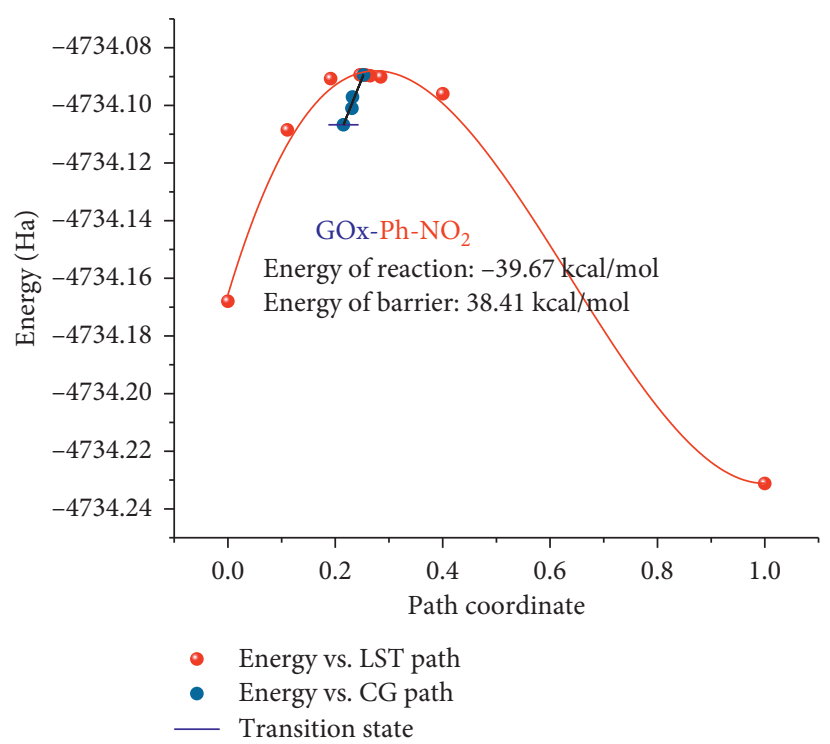

(d)

FIGURE 4: Graph of homolytic BDE of (a) phenyldiazonium and (b) nitrophenyldiazonium cations together with the corresponding TS search energy trajectories for the grafting reaction of (c) phenyl radicals and (d) nitrophenyl radicals onto the graphene oxide surface.

aryldiazonium salts on different bulk or nanoscopic carbons is well known [3]. Thus, in order for the grafting reactions to take place spontaneously, a plausible route will be initiated through the instability of aryldiazonium cations. The grafting reactions after their initiations are sustained by the energy gain from the difference between the reaction energy $(-37.86 \mathrm{kcal} / \mathrm{mol}$ phenyl radical, -39.76 nitrophenyl $\mathrm{radical})$ and the energy barrier for the grafting reaction $(35.28 \mathrm{kcal} /$ mol for phenyldiazonium and $38.41 \mathrm{kcal} / \mathrm{mol}$ nitrophenyldiazonium) to take place.

\section{Conclusion}

In this work, the adsorption, grafting, and activation energy of aryldiazonium cations onto the graphene oxide surface were studied. The adsorption energy results showed that the interaction strength is up to $-45 \mathrm{kcal} / \mathrm{mol}$, pointing out to chemisorption. The adsorption of these cations onto the graphene oxide is through the van der Waals interactions. The bond dissociation energy for the grafted layer is high ( $\approx 66 \mathrm{kcal} / \mathrm{mol}$ ), showing that the formed interface is quite stable. Comparing the BDE value for the scission of diazonium cation to its radical, with the values of the energy barrier and the reaction energy, it supports that the grafting reaction for this substrate is barrierless, meaning that the grafting reaction will proceed with the adsorption of the diazonium cation, nitrogen bond section, and the grafting of the formed aryl radical. This work will contribute to the detailed molecular understanding of the adsorption/grafting chemistry of the aryldiazonium cations, respectively, and 
aryl radicals onto graphene oxide and other graphene-like materials.

\section{Data Availability}

The data used to support the findings of this study are included within the article.

\section{Disclosure}

Part of the results was presented at the 25th Congress of SCTM.

\section{Conflicts of Interest}

The author declares that there are no conflicts of interest.

\section{Acknowledgments}

The author gratefully acknowledges the support from the Ministry of Education, Science and Technology of Kosovo (No. 2-5069), for providing him with the computing resources.

\section{References}

[1] M. Delamar, R. Hitmi, J. Pinson, and J. M. Saveant, "Covalent modification of carbon surfaces by grafting of functionalized aryl radicals produced from electrochemical reduction of diazonium salts," Journal of the American Chemical Society, vol. 114, no. 14, pp. 5883-5884, 1992.

[2] S. P. Pujari, L. Scheres, A. T. M. Marcelis, and H. Zuilhof, "Covalent surface modification of oxide surfaces," Angewandte Chemie International Edition, vol. 53, no. 25, pp. 6322-6356, 2014.

[3] A. Berisha, M. Chehimi, J. Pinson, and F. Podvorica, "Electrode surface modification using diazonium salts," in Electroanalytical Chemistry: A Series of Advances, Taylor \& Francis, Didcot, UK, 2015.

[4] A. J. Downard and M. J. Prince, "Barrier properties of organic monolayers on glassy carbon electrodes," Langmuir, vol. 17, no. 18, pp. 5581-5586, 2001.

[5] S. Baranton and D. Bélanger, "Electrochemical derivatization of carbon surface by reduction of in situ generated diazonium cations," Journal of Physical Chemistry B, vol. 109, no. 51, pp. 24401-24410, 2005.

[6] A. Berisha, C. Combellas, F. Kanoufi et al., "Alkyl-modified gold surfaces: characterization of the Au-C bond," Langmuir, vol. 34, no. 38, pp. 11264-11271, 2018.

[7] F. Mirkhalaf, T. J. Mason, D. J. Morgan, and V. Saez, "Frequency effects on the surface coverage of nitrophenyl films ultrasonically grafted onto indium tin oxide," Langmuir, vol. 27, no. 5, pp. 1853-1858, 2011.

[8] L. Zhang, J. Xia, Q. Zhao, L. Liu, and Z. Zhang, "Functional graphene oxide as a nanocarrier for controlled loading and targeted delivery of mixed anticancer drugs," Small, vol. 6, no. 4, pp. 537-544, 2010.

[9] A. Wang, W. Yu, Z. Huang et al., "Covalent functionalization of reduced graphene oxide with porphyrin by means of diazonium chemistry for nonlinear optical performance," Scientific Reports, vol. 6, no. 1, p. 23325, 2016.

[10] V. Rebuttini, E. Fazio, S. Santangelo et al., "Chemical modification of graphene oxide through diazonium chemistry and its influence on the structure-property relationships of graphene oxide-iron oxide nanocomposites," Chemistry- $A$ European Journal, vol. 21, no. 35, pp. 12465-12474, 2015.

[11] J. P. Perdew, K. Burke, and M. Ernzerhof, "Generalized gradient approximation made simple," Physical Review Letters, vol. 77, no. 18, pp. 3865-3868, 1996.

[12] A. Berisha, C. Combellas, F. Kanoufi et al., "Some theoretical and experimental insights on the mechanistic routes leading to the spontaneous grafting of gold surfaces by diazonium salts," Langmuir, vol. 33, no. 35, pp. 8730-8738, 2017.

[13] M. Seydou, K. Lassoued, F. Tielens, F. Maurel, F. Raouafi, and B. Diawara, "A DFT-D study of hydrogen adsorption on functionalized graphene," RSC Advances, vol. 5, no. 19, pp. 14400-14406, 2015.

[14] S. Gautier, S. N. Steinmann, C. Michel, P. Fleurat-Lessard, and P. Sautet, "Molecular adsorption at Pt(111). How accurate are DFT functionals?," Physical Chemistry Chemical Physics, vol. 17, no. 43, pp. 28921-28930, 2015.

[15] S. Tang and Z. Cao, "Adsorption and dissociation of ammonia on graphene oxides: a first-principles study," Journal of Physical Chemistry C, vol. 116, no. 15, pp. 8778-8791, 2012.

[16] S. Tang and Z. Cao, "Adsorption of nitrogen oxides on graphene and graphene oxides: insights from density functional calculations," Journal of Chemical Physics, vol. 134, no. 4, article 044710, 2011.

[17] J. Greenwood, T. H. Phan, Y. Fujita et al., "Covalent modification of graphene and graphite using diazonium chemistry: tunable grafting and nanomanipulation," ACS Nano, vol. 9, no. 5, pp. 5520-5535, 2015.

[18] L. Cheng, T. Xu, W. Li et al., "Density functional theory investigation into the $\mathrm{B}$ and $\mathrm{Ga}$ doped clean and water covered $\gamma$-alumina surfaces," Journal of Chemistry, vol. 2017, Article ID 6215315, 7 pages, 2017.

[19] Y. Inada and H. Orita, "Efficiency of numerical basis sets for predicting the binding energies of hydrogen bonded complexes: evidence of small basis set superposition error compared to gaussian basis sets," Journal of Computational Chemistry, vol. 29, no. 2, pp. 225-232, 2007.

[20] N. Ding, X. Chen, and C.-M. L. Wu, "Interactions between polybrominated diphenyl ethers and graphene surface: a DFT and MD investigation," Environmental Science: Nano, vol. 1, no. 1, pp. 55-63, 2014.

[21] A. Klamt, "The COSMO and COSMO-RS solvation models," Wiley Interdisciplinary Reviews: Computational Molecular Science, vol. 8, no. 1, article e1338, 2017.

[22] N. Govind, M. Petersen, G. Fitzgerald, D. King-Smith, and J. Andzelm, "A generalized synchronous transit method for transition state location," Computational Materials Science, vol. 28, no. 2, pp. 250-258, 2003.

[23] Y. Shudo, M. R. Karim, R. Ohtani, M. Nakamura, and S. Hayami, "Hybrids from the $\pi-\pi$ stacking of graphene oxide and aromatic sulfonic compounds for improved proton conductivity," ChemElectroChem, vol. 5, no. 2, pp. 238-241, 2017.

[24] P. Hobza and J. Řezáč, "Introduction: noncovalent interactions," Chemical Reviews, vol. 116, no. 9, pp. 4911-4912, 2016.

[25] T. Lu and F. Chen, "Multiwfn: a multifunctional wavefunction analyzer," Journal of Computational Chemistry, vol. 33, no. 5, pp. 580-592, 2011. 

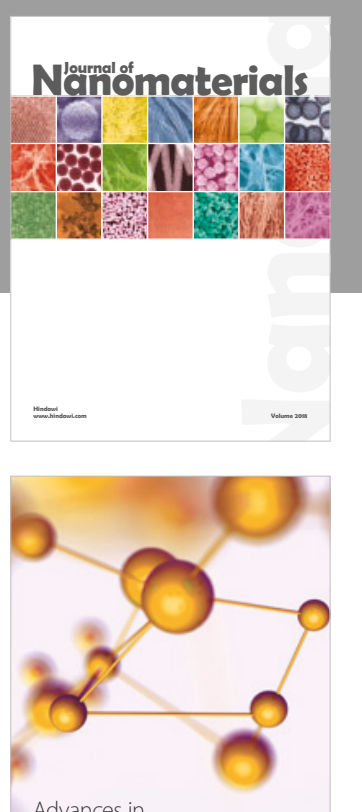

Physical Chemistry
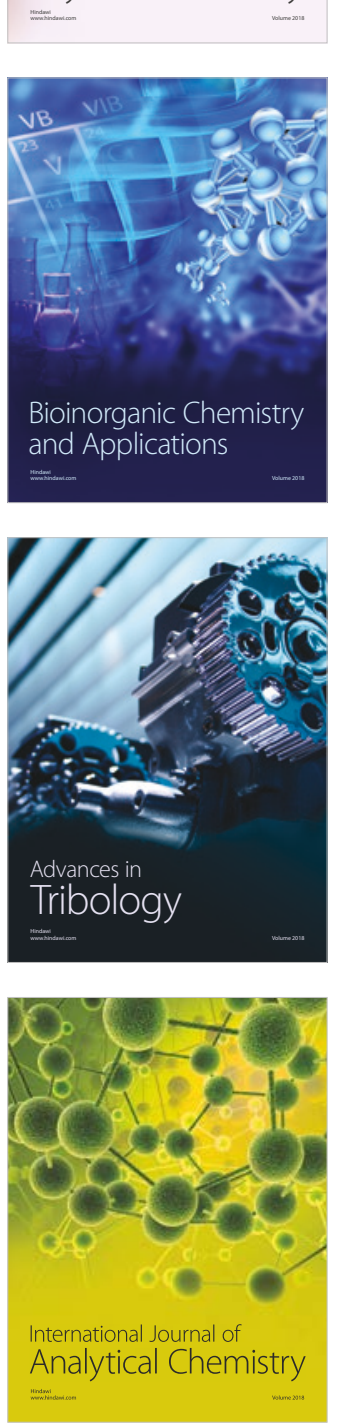

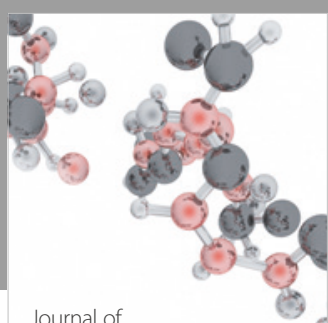

Analytical Methods

in Chemistry

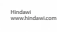

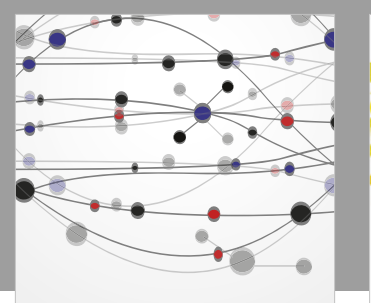

The Scientific World Journal

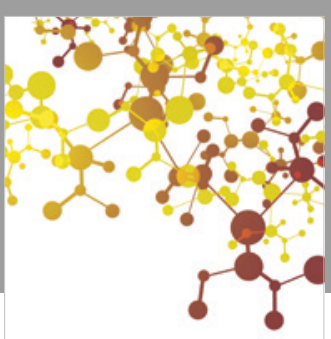

Journal of

Applied Chemistry
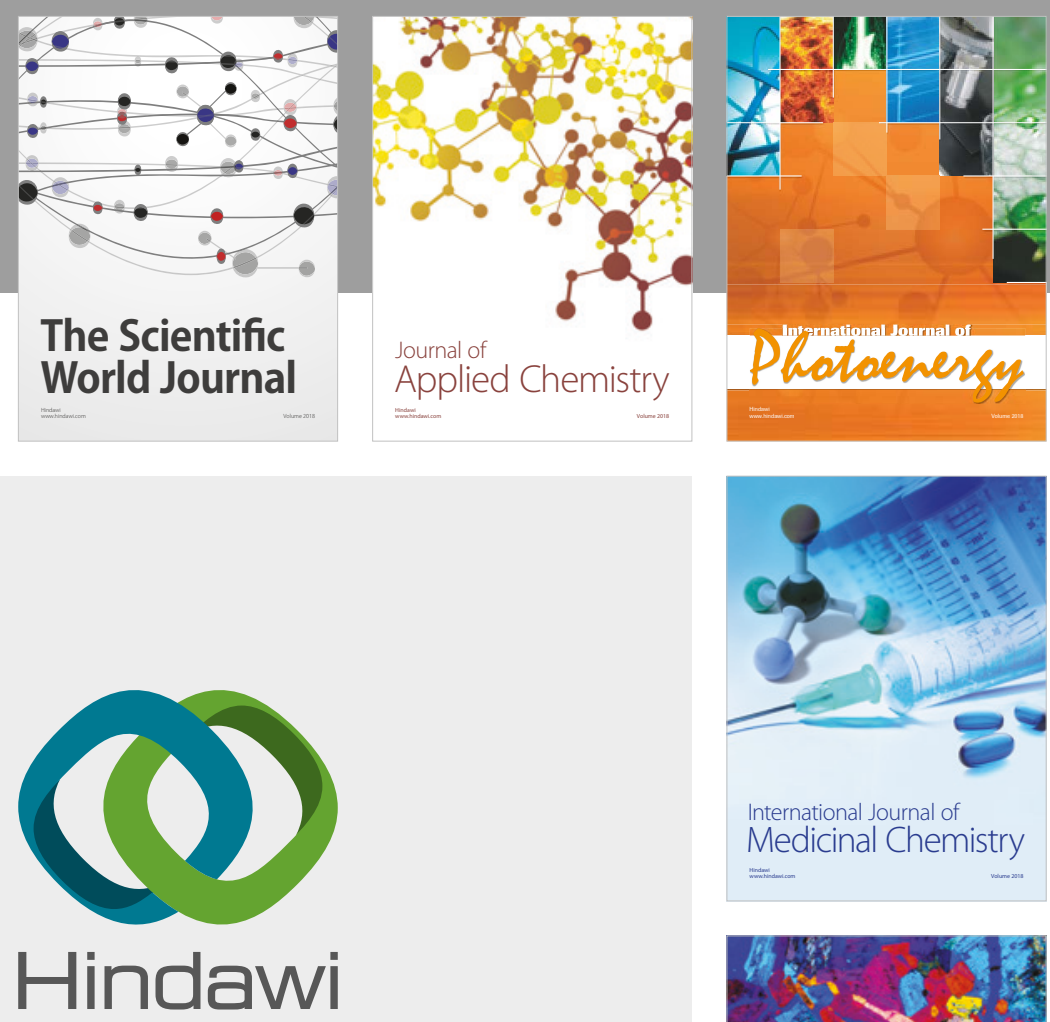

Submit your manuscripts at

www.hindawi.com
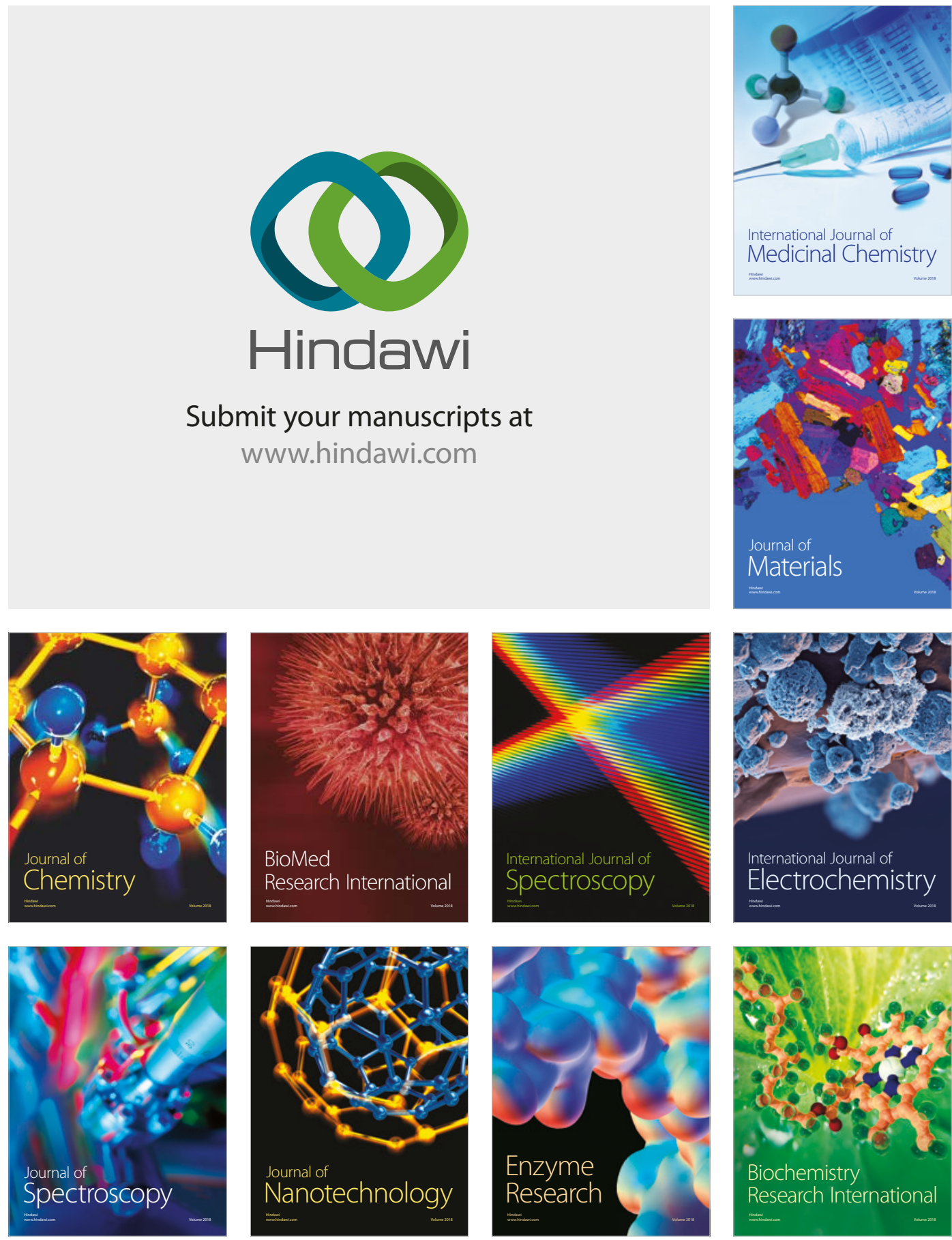
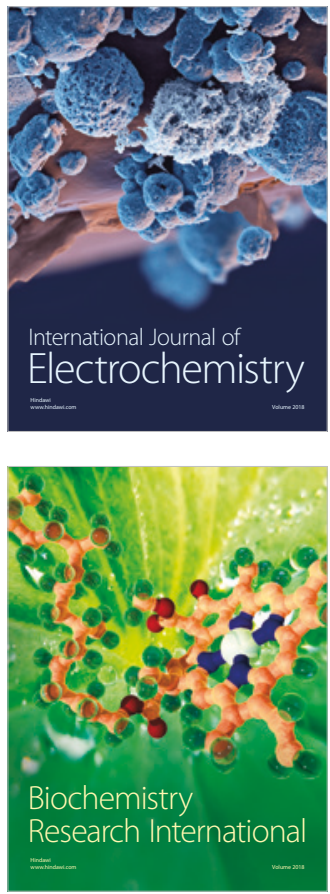